\title{
Currarino syndrome: repair of the dysraphic anomalies and resection of the presacral mass in a combined neurosurgical and general surgical approach
}

\author{
Michael D. Cearns, MBBS, BSc, ${ }^{1}$ Samantha Hettige, FRCS(SN), ${ }^{1}$ Paolo De Coppi, MD, PhD, ${ }^{2}$ and \\ Dominic N. P. Thompson, FRCS(SN) ${ }^{1}$ \\ 1Department of Paediatric Neurosurgery and ${ }^{2}$ Specialist Neonatal and Paediatric Surgery, Great Ormond Street Hospital, \\ London, United Kingdom
}

OBJECTIVE It is well established that Currarino syndrome (CS) may be associated with spinal dysraphism. Here, the authors report on $10 \mathrm{CS}$ patients with dysraphic anomalies who had undergone a combined neurosurgical and general surgical approach to repair the dysraphic anomalies and resect the presacral mass in a single operation. They discuss the spectrum of spinal dysraphism that may coexist in CS in the context of its developmental etiology.

METHODS Children with a confirmed CS diagnosis who had undergone the combined operative approach were identified from a departmental database. Presenting features were recorded and preoperative imaging was analyzed to record features of the presacral mass and the dysraphic anomalies. The histopathological nature of the resected presacral mass and the outcomes postoperatively and at the last follow-up were reviewed.

RESULTS Between 2008 and 2015, 10 patients presented with CS, 9 with constipation. Median age at the time of surgery was 1.3 years. Six of the 10 patients had anorectal malformation consisting of anal stenosis, rectal stenosis, or imperforate anus. Spinal anomalies included anterior meningocele (5 cases), low-lying conus (8), terminal syrinx (4), fatty filum (5), caudal lipoma (3), and intraspinal cyst (1). In all cases, the lumbosacral spinal canal was accessed via a midline approach with laminoplasty, allowing spinal cord untethering and repair of the dysraphic anomalies. Following dural closure, the incision was extended inferiorly to incorporate a posterior sagittal approach to resect the presacral mass. The histopathological nature of the mass was mature teratoma (8 cases), complex hamartomatous malformation (1), or neurenteric cyst (1). There were no new instances of neurological deterioration, with most instances of persisting morbidity related to constipation (6 cases) or neurogenic bladder dysfunction (8). There were no infective complications, no instances of cerebrospinal fluid fistula, no recurrences of the presacral mass, and no cases of retethering of the spinal cord.

CONCLUSIONS Although not part of the original triad, spinal dysraphic anomalies are common in CS and in keeping with a disorder of secondary neurulation. Lumbosacral MRI is an essential investigation when CS is suspected. Children are at risk of sphincter impairment due to the anorectal malformation; however, both spinal cord tethering and compression from the presacral mass may further compromise long-term continence. A combined operative approach to repair the dysraphic anomalies and resect the presacral mass is described with good postoperative and long-term outcomes. https://thejns.org/doi/abs/10.3171/2018.5.PEDS17582

KEYWORDS Currarino syndrome; anorectal malformation; spinal dysraphism; anterior meningocele; teratoma; tethered spinal cord; spine

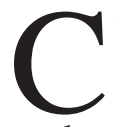
URRARINO syndrome (CS) is a rare constellation of congenital malformations affecting the caudal spine and its surrounding structures and is considered to be a form of caudal regression anomaly that occurs during embryonic development., ${ }^{1,5}$ Although classically defined as the triad of sacral dysgenesis, anorectal malformation, and presacral mass, CS is now recognized to be a more complex clinical spectrum that can involve various pathologies. ${ }^{57,17}$ These include occult spinal dysraphism, spinal cord tethering, renal/ureteral anomalies, female in- 
ternal genital or uterine malformations, and various types of fistulas (rectoperineal, rectourethral, rectovestibular, rectocloacal, and neurenteric fistulas have all been described) ${ }^{7,13,17}$

Currarino syndrome has a genetic basis, and in familial cases, inheritance is autosomal dominant with low penetrance. The homeobox gene motor neuron and pancreas homeobox-1 (MNX1, formerly HLXB9) is implicated in almost all familial cases and $30 \%$ of sporadic cases of CS. ${ }^{1,4,19}$ Eighty-two causative mutations have been identified on this gene, which is mapped to the $7 \mathrm{q} 36$ region and encodes a transcription factor, although these have so far not been correlated well to phenotype. . $^{4,13,19}$

Even within the triad originally described, the phenotype is variable and the presence of two components of the triad is often termed "incomplete CS." ",15 The typical sacral anomaly is a scimitar-shaped hemisacrum with sparing of the first sacral vertebra. ${ }^{1,7,23}$ The most common anorectal malformations are anal stenosis, rectoperineal fistula, and imperforate anus, and in most cases the presacral mass is an anterior meningocele, a teratoma, or a combined pathology. $7,9,11,17,22$

It is recognized that spinal dysraphism, while not an obligatory component of the syndrome, can be a feature of CS that may require neurosurgical intervention. . $^{7,13}$ Most commonly the dysraphism occurs in the form of an anterior meningocele, which in the context of CS often contributes to the presacral mass by herniation through an anterior sacral defect. However, other distinct spinal pathologies have been described, including spinal lipoma, fatty filum with low-lying conus, syringomyelia, diastematomyelia, and fistula between the colon or bladder and the spinal canal. ${ }^{9,13,17}$ A recent literature review by Kole and colleagues ${ }^{13}$ revealed that occult spinal dysraphism was present in $60 \%$ of 110 patients and that $43 \%$ of 163 patients underwent a procedure to correct a tethered spinal cord.

In the current study, we present a case series of $10 \mathrm{CS}$ patients with associated spinal dysraphism who had presented to our service between 2008 and 2015 and were treated with a combined neurosurgical and general surgical approach to repair the spinal dysraphism and resect the presacral mass in a single operation.

\section{Methods}

Patients were identified from a prospectively collected departmental database containing all neurosurgical procedures undertaken in the department, along with any adverse events or complications of surgery. The study group comprised all patients with a diagnosis of CS who had undergone a combined neurosurgical and general surgical approach to repair the spinal dysraphism and resect the presacral mass in a single operation. Children with CS who had undergone either neurosurgical or general surgical procedures alone were excluded from the study. The demographic parameters assessed were age at presentation, sex, and family history.

Cases were evaluated by a review of clinical records, radiological studies, operative reports, and histopathological results. The mode of clinical presentation was record- ed and the preoperative radiological images (plain radiographs and MR images) were analyzed to record features of the presacral mass as well as the nature of the dysraphic and sacral anomalies. The histopathological nature of the resected presacral mass was determined from histological reports, and clinical records were used to assess perioperative complications and functional status at the last follow-up.

\section{Results}

Ten patients were eligible for inclusion in this study $(6$ female, 4 male), all of whom had undergone surgery between 2008 and 2015. All patients had evidence of sacral dysgenesis and a presacral mass (minimal requirements for incomplete CS) along with an associated spinal dysraphism. Six of the 10 patients also had an anorectal malformation, encompassing the complete CS phenotype. Median age at the time of surgical intervention was 1.3 years (mean 2.4 years, range 20 days -11 years).

\section{Presentation}

Case-specific details, including presenting features and radiological findings, are summarized in Table 1. By far the most common initial symptom was constipation, with almost all patients $(9 / 10)$ presenting with this sign. Among these 9 patients, 3 had clinical features of bowel obstruction with vomiting and abdominal distention soon after birth. Anorectal malformation, which was diagnosed in $6 / 10$ patients, encompassed a combination of imperforate anus (3), anal stenosis (2), rectal stenosis (1), and anteriorly displaced anus (1). Four of the 10 patients had documented evidence of urinary tract dysfunction prior to the combined intervention, comprising 1 case each of urinary incontinence, urinary retention, mixed symptoms, and hydronephrosis. Evidence was based on clinical symptoms as well as a noninvasive preoperative bladder function assessment consisting of an upper and a lower urinary tract ultrasound, as well as an evaluation of urinary flow rates and quantification of bladder emptying using pre- and postvoid bladder volumes averaged over three voids. $\mathrm{Cu}-$ taneous stigmata of occult spinal dysraphism in the form of sacral swelling and/or hairy patch were present in $2 / 10$ patients. Three of the 10 patients had evidence of bilateral leg weakness on neurological examination, and in 1 case, CS was incidentally diagnosed on MRI performed for global developmental delay and prophylactic surgery was proposed. In another case, severe anal stenosis was identified soon after birth. The child had undergone anal dilatation and examination under anesthesia at another unit. This was followed by the introduction of daily dilatation with Hagar dilators. The child presented at 10 weeks with bilateral leg weakness and neurogenic bladder dysfunction secondary to spinal epidural abscess associated with pyomyelia.

A positive family history was present in $3 / 10$ patients. Interestingly, these 3 patients were siblings, 2 of whom were nonidentical twins and all presenting with clinical features of bowel obstruction. Another 2 patients were found to have a genetic deletion at the 7q36 locus, which has been associated with CS. 
TABLE 1. Case-specific details including presenting features and radiological and histopathological findings

\begin{tabular}{|c|c|c|c|c|c|c|c|c|}
\hline $\begin{array}{l}\text { Case } \\
\text { No. }\end{array}$ & $\begin{array}{l}\text { Age at } \\
\text { Op }\end{array}$ & Sex & Presenting Feature & $\begin{array}{c}\text { Anorectal } \\
\text { Malformation }\end{array}$ & Sacral Defect & $\begin{array}{l}\text { Dysraphic } \\
\text { Anomaly }\end{array}$ & $\begin{array}{l}\text { Conus } \\
\text { Level }\end{array}$ & Presacral Mass \\
\hline 1 & 20 days & $M$ & Constipation & Anal stenosis & $\begin{array}{l}\text { Dysgenesis distal to } S 2 \text {, ant sacral } \\
\text { defect, rt sacral deficiency }\end{array}$ & $\begin{array}{l}\text { Ant meningocele, } \\
\text { filar lipoma }\end{array}$ & L4 & Mature teratoma \\
\hline 2 & $18 \mathrm{mos}$ & $\mathrm{F}$ & $\begin{array}{c}\text { Motor weakness, sacral } \\
\text { swelling, hairy patch }\end{array}$ & - & $\begin{array}{l}\text { Dysgenesis distal to } \mathrm{S} 2 \text {, ant sacral } \\
\text { defect, rt sacral deficiency }\end{array}$ & $\begin{array}{l}\text { Filar lipoma, } \\
\text { syringomyelia }\end{array}$ & L3 & Mature teratoma \\
\hline 3 & 22 mos & $\mathrm{F}$ & Constipation & - & $\begin{array}{l}\text { Dysgenesis distal to } S 3 \text {, ant sacral } \\
\text { defect, rt sacral deficiency }\end{array}$ & Intraspinal cyst & L3 & Neurenteric cyst \\
\hline 4 & $2.5 \mathrm{mos}$ & $\mathrm{F}$ & $\begin{array}{l}\text { Constipation, motor } \\
\text { weakness, neuro- } \\
\text { genic bladder }\end{array}$ & Imperforate anus & $\begin{array}{l}\text { Dysgenesis distal to S2, ant sacral } \\
\text { defect }\end{array}$ & $\begin{array}{l}\text { Caudal lipoma, } \\
\text { pyomyelia }\end{array}$ & S3 & Mature teratoma \\
\hline 5 & $2.5 \mathrm{yrs}$ & M & $\begin{array}{l}\text { Constipation, urinary } \\
\text { retention }\end{array}$ & - & $\begin{array}{l}\text { Dysgenesis distal to } S 3 \text {, ant sacral } \\
\text { defect, rt sacral deficiency }\end{array}$ & $\begin{array}{l}\text { Ant meningocele, } \\
\text { filar lipoma }\end{array}$ & L2-3 & Mature teratoma \\
\hline 6 & $18 \mathrm{mos}$ & M & $\begin{array}{l}\text { Constipation, develop- } \\
\text { mental delay }\end{array}$ & - & $\begin{array}{l}\text { Dysgenesis distal to S2, ant sacral } \\
\text { defect }\end{array}$ & $\begin{array}{l}\text { Caudal lipoma, } \\
\text { syringomyelia }\end{array}$ & S1 & Mature teratoma \\
\hline 7 & $11 \mathrm{yrs}$ & $\mathrm{F}$ & $\begin{array}{l}\text { Constipation, urinary } \\
\text { incontinence, sacral } \\
\text { swelling }\end{array}$ & Anal stenosis & $\begin{array}{l}\text { Dysgenesis distal to S2, ant sacral } \\
\text { defect }\end{array}$ & $\begin{array}{c}\text { Ant meningocele, } \\
\text { caudal lipoma, } \\
\text { syringomyelia }\end{array}$ & L5 & Mature teratoma \\
\hline 8 & $4.5 \mathrm{yrs}$ & M & Constipation & Imperforate anus & $\begin{array}{l}\text { Dysgenesis distal to } S 2 \text {, ant sacral } \\
\text { defect, rt sacral deficiency }\end{array}$ & $\begin{array}{l}\text { Filar lipoma, } \\
\text { syringomyelia }\end{array}$ & L3 & $\begin{array}{r}\text { Hamartomatous } \\
\text { malformation }\end{array}$ \\
\hline 9 & $6.5 \mathrm{mos}$ & $\mathrm{F}$ & $\begin{array}{l}\text { Constipation, hydrone- } \\
\text { phrosis }\end{array}$ & $\begin{array}{l}\text { Anteriorly dis- } \\
\text { placed imperfo- } \\
\text { rate anus }\end{array}$ & $\begin{array}{l}\text { Dysgenesis distal to } \mathrm{S} 1 \text {, ant sacral } \\
\text { defect, It sacral deficiency }\end{array}$ & Ant meningocele & L3 & Mature teratoma \\
\hline 10 & 38 days & $\mathrm{F}$ & Constipation & Rectal stenosis & $\begin{array}{l}\text { Dysgenesis distal to } S 2 \text {, ant sacral } \\
\text { defect, rt sacral deficiency }\end{array}$ & $\begin{array}{l}\text { Ant meningocele, } \\
\text { filar lipoma }\end{array}$ & L2 & Mature teratoma \\
\hline
\end{tabular}

Ant = anterior; $-=$ none.

\section{Radiological Findings}

Plain Radiograph Findings

All 10 patients had evidence of partial sacral dysgenesis. It always spared the $\mathrm{S} 1$ vertebra; in 7 cases the defect was distal to $\mathrm{S} 2$, and in 2 cases the defect was distal to S3. In $7 / 10$ cases there was a classic "scimitar sacrum" with a right (6 cases) or left (1 case) sacral deficiency on a posteroanterior plain radiograph (Fig. 1). All patients had evidence of an anterior sacral defect confirmed by plain radiography or MRI.

\section{MRI Findings}

In all cases MRI of the lumbosacral region was performed. The intraspinal anomalies are summarized in Table 1. A low-lying conus was observed in 8/10 patients. The average level of the conus was at the L4 vertebra (range L2-S3), and the L2/L3 intervertebral disc was used as the lower limit of the normal conus position. This was often associated with fatty filum (also termed "filar lipoma"), which was present in 5 cases. A larger lipoma of the caudal type was present in 3 cases, and these patients had the lowest conus levels observed in this study. Anterior meningocele, defined as a presacral cerebrospinal fluid-containing sac in continuity with the spinal theca, was present in 5/10 patients. In these cases, the meningocele herniated ventrally through the anterior sacral defect, where it contributed to the mass in the presacral space (Fig. 2). A terminal syrinx, defined as any MRI evidence of fluid in the terminal spinal cord, was present in $4 / 10$

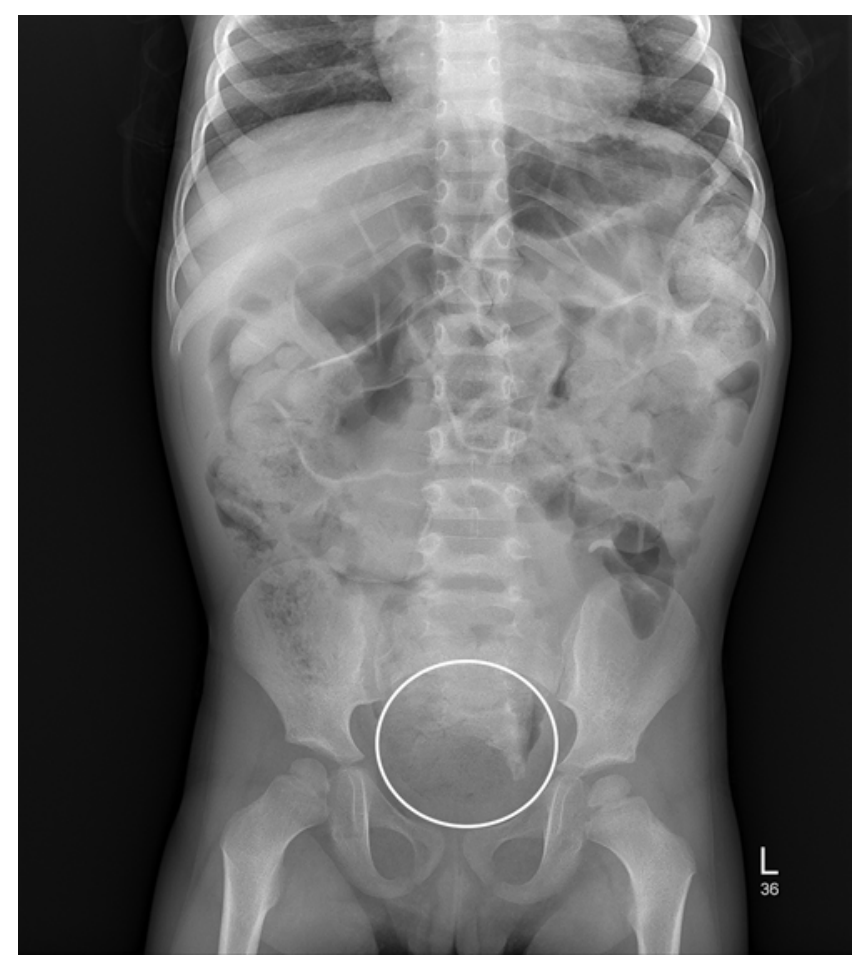

FIG. 1. Plain radiograph showing the typical scimitar-shaped sacral dysgenesis of CS, with the sacral deficiency on the right (circle). 
patients. Furthermore, 1 patient had an intraspinal cyst and 1 patient had a spinal epidural abscess with extensive pyomyelia. No single patient had an isolated dysraphic anomaly; the average incidence of concurrent anomalies was 2.6 (range $2-4$ ).

\section{Operative Approach}

Patients underwent a combined neurosurgical and general surgical approach to repair the dysraphic anomalies and resect the presacral mass in a single operation. Intraoperative neurophysiological monitoring was used in all cases, which involved a combination of motor evoked potentials and triggered electromyographic mapping, with electrodes placed in the tibialis anterior muscle (L5), gastrocnemius muscle (S1), abductor hallucis muscle (S2), and anal sphincter (S3/S4). Patients were positioned prone after insertion of a urinary catheter. The lumbosacral spinal canal was accessed through a standard midline approach with laminoplasty. The dura mater was opened in the midline. Untethering of the spinal cord was performed by section of the filum or division of the caudal lipoma once the functional nerve roots had been identified via nerve root mapping. When present the anterior sacral meningocele was repaired through the same approach. The neck of the ventrally (and caudally) positioned meningocele sac was delineated (Fig. 3 left). The posterior dural opening was then closed from proximal to distal, until this closure was level with the anterior defect. The posterior and anterior dura were then sutured perpendicular to the main dural closure. A T-shaped duraplasty thus recreated the terminal thecal sac, effectively excluding the neck and sac of the anterior meningocele (Fig. 3 right).

Once the dural closure was complete, the skin incision was extended to the posterior margin of the anus. Since the coccyx and terminal sacral segments are generally absent, there is good transperineal access to the presacral space. From beneath the surgical drapes, and thus outside the sterile field, a Hagar dilator was placed through the anus to the rectum in order to protect the latter during mobilization of the anterior aspect of the presacral mass. The posterior aspect of the mass from the sacrum and sacral defect could then be safely dissected, having already excluded and made watertight the intrathecal compartment. Posterior sagittal anorectoplasty or anoplasty was performed in the same setting when required.

In $4 / 10$ cases, a colostomy was formed in the neonatal period as management of the anal anomaly. In each of these cases, the colostomy was reversed within several months following the combined operation.

\section{Histopathological Analysis}

The most common finding was mature teratoma, present in $8 / 10$ cases. In 1 case, the presacral mass was deemed to be a complex hamartomatous malformation consisting of multiple tissue elements, including meningeal elements. There was also 1 case of neurenteric cyst. There were no instances of malignancy in this series.

\section{Outcomes}

No major neurosurgical complications were associated

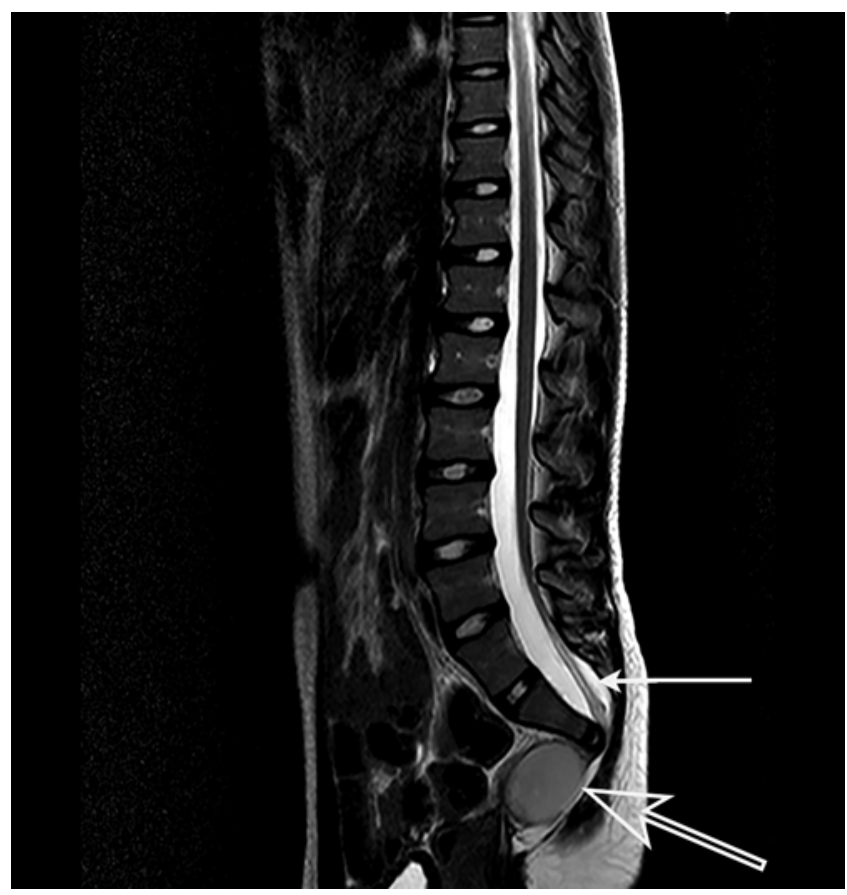

FIG. 2. Sagittal T2-weighted MR image showing a low-lying conus with evidence of spinal cord tethering (solid arrow), sacral dysgenesis, and a cystic presacral mass (open arrow).

with this operative procedure. There was one instance of a minor superficial wound complication, which was successfully treated conservatively. In a second case, a coccygeal granuloma formed 6 months postoperatively, and at 1 year postoperatively the patient suffered a perianal abscess as part of an anal fistula. Another patient developed small-bowel volvulus around a band adhesion 14 months postoperatively, requiring an emergency laparotomy with bowel resection and formation of a stoma, which was reversed 7 months later. There were no cases of meningitis, cerebrospinal fluid leak, or hematoma at any point in the follow-up of these patients. There were no instances of new neurological or urological dysfunction following surgery. At the last follow-up, there were no recurrences of the presacral mass and no cases of spinal cord retethering requiring further operative intervention.

At the time of writing, patients had been followed up for an average of 5.3 years (range 2-9.3 years). At the last follow-up, all patients were free of pain and were mobilizing independently. Two patients have been slow to walk in the context of a global developmental delay, and a third has ongoing irreversible weakness following her presentation with extensive pyomyelia. In the remaining 7 cases, lower limb motor function is normal. Eight of 10 patients have ongoing urological issues consisting of urinary incontinence (1), occasional nocturnal enuresis (3), incomplete bladder emptying (3), and ureteral dilatation (1). In at least 1 patient the urological issue was thought to be secondary to ongoing constipation; in the remaining 7, the findings were consistent with neurogenic sphincter disturbance. Two patients are currently catheterized intermittently. At the last follow-up, all patients were free of urinary tract infection. Six of the 10 patients have problems 

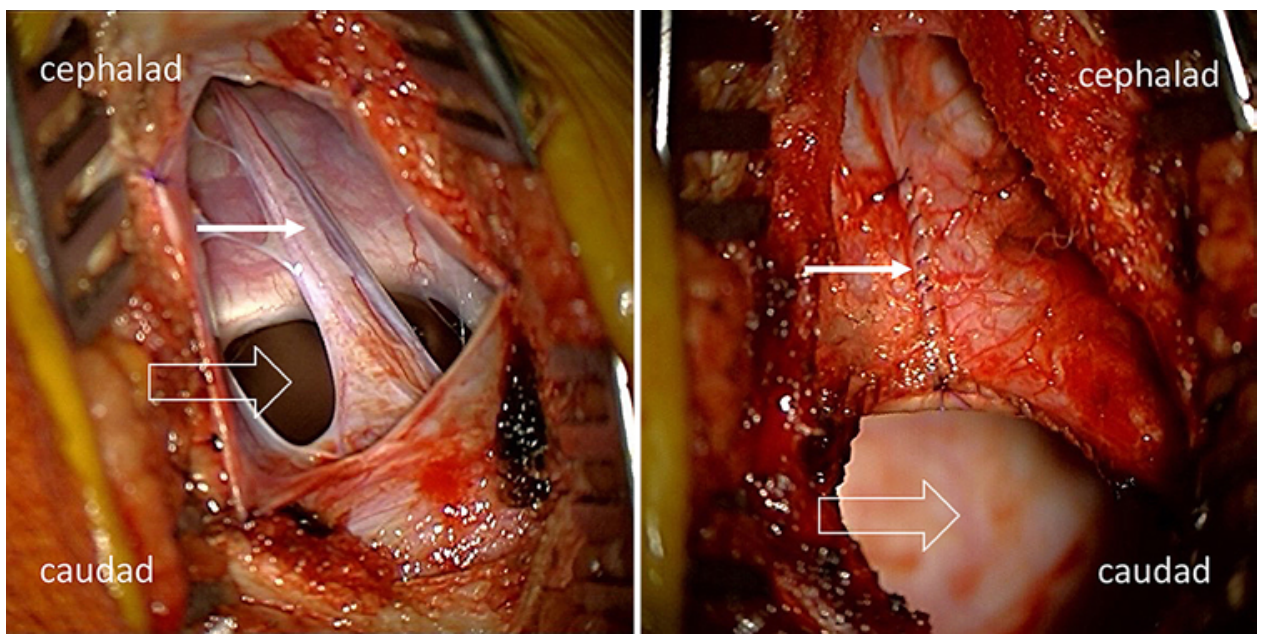

FIG. 3. Intraoperative view of the terminal spinal cord before and after surgical untethering. Left: A tethered spinal cord (solid arrow) and the neck of an anterior sacral meningocele. There is an anterior sacral defect communicating with the presacral mass (open arrow). Right: Appearance after untethering of the spinal cord. The terminal thecal sac has been reconstructed using a T-shaped duraplasty (solid arrow), excluding the communication with the presacral space (open arrow). Cephalad and caudad directions are indicated for orientation. Figure is available in color online only.

with constipation, and 1 of these patients has intermittent fecal soiling. In 3 patients, an antegrade continence enema (ACE) stoma has been formed, and 1 of these patients is completely free of constipation. Of the 6 patients with ongoing constipation, 5 have concurrent urological issues.

\section{Discussion \\ Operative Approach}

We believe this is the largest case series to report on transsacral access to the spinal cord as well as posterior sagittal access to the presacral space to provide singlestage combined operative management of CS with spinal dysraphism. According to the literature, a wide variety of approaches to this condition have been taken. Some groups have used a staged approach, performing posterior sagittal anorectoplasty and repair of anterior meningocele in separate procedures., ${ }^{7,16,17}$ Some have proposed that this approach reduces the risk of postoperative meningitis. ${ }^{11,15}$ Other approaches described have included a posterior sagittal approach for the repair of an anterior meningocele, a transsacral approach to the presacral mass, and a combined anterior and posterior approach. ${ }^{9,13,15,18,23}$ There are case reports and small case series that feature a combined approach to the presacral mass and dysraphic anomalies via lumbosacral laminectomy. ${ }^{13,14}$ However, the singlestage combined approach advocated in the present study has, to our knowledge, only been described in individual case reports. $2,10,20,21,23$

This variability in the management of CS reflects a lack of consensus among the clinical community, most likely rooted in a paucity of evidence supporting a particular approach to this rare syndrome. Operative intervention is indicated in CS for several reasons. Firstly, in the face of chronic and progressive symptoms, it is considered beneficial to treat the underlying cause, be that the anorectal malformation, the presacral mass, or the spinal dysraphism. Secondly, without intervention, patients are at risk of life-threatening complications, such as recurrent meningitis, perianal sepsis, and, as demonstrated in the present series, pyomyelia. ${ }^{7,12}$ Finally, when a malignant teratoma cannot be excluded, it is considered necessary to resect the presacral mass and confirm its histology. ${ }^{9}$ Here, we demonstrate that a single-stage operation can safely and effectively address each of these indications simultaneously in a larger number of patients than has been previously described. Contrary to speculation, we found no cases of postoperative meningitis despite operative access to the spinal cord and posterior rectum in the same sitting. Importantly, in the case of an extensive rectoperineal approach, a covering colostomy was performed, as is routine for anorectal reconstruction in our department. Furthermore, there were no cases of cerebrospinal fluid leak or hematoma, although there was one case of perianal abscess associated with a fistula-in-ano 1 year after the operation, one case of adhesional small-bowel volvulus 14 months postoperatively, and one case of superficial wound dehiscence. However, none of these complications related specifically to the use of the combined operative approach. At the last follow-up, all patients had good motor outcomes and were not in pain. There were no instances of surgery for retethering of the spinal cord in this series. By safely achieving multiple objectives in a single sitting, this approach has the important advantages of reducing the number of general anesthesia episodes, scar formation after multiple operations, and the number of admissions for children and their families.

It is important to note the two main causes of long-term morbidity in this study. Ongoing bladder disturbance, including various degrees of urinary incontinence and incomplete bladder emptying, affected the majority of patients. Constipation represented the other main cause of postoperative long-term morbidity, with one case of intermittent fecal soiling postoperatively. In most cases, bladder and bowel symptoms occurred in combination. 
Where outcomes related to bladder and bowel function are specifically mentioned in other studies, it appears that both ongoing constipation and urinary incontinence have been a feature regardless of the operative approach and that both are thought to have been underestimated previously. ., $, 15-17,23$ Indeed, this may be rooted in the etiology of the condition rather than the effects of surgery; it has been proposed that neurogenic sphincter disturbance may underlie these causes of morbidity in CS.22,24 We found combined bowel and bladder symptoms consistent with neurogenic sphincter disturbance. This may be a result of primary dysgenesis of the terminal spinal cord and conus rather than tethering of the spinal cord. However, since it is not possible to reliably differentiate between these etiologies and given that the surgical anatomy of the tethered cord in these cases is generally straightforward, we would advocate incorporating spinal cord untethering into the treatment strategy.

\section{Developmental Etiology}

Currarino et al. originally postulated that the etiology of the condition may lie in the splitting of the notochord during late gastrulation, causing abnormal ecto-endodermal adhesions, disruption of somite development, amalgamation of multiple germ layers, and thus a wide range of defects seen at birth. ${ }^{5}$ It is now recognized that the caudal cell mass, a derivative of the primitive streak, which gives rise to the cloaca (and therefore the distal gastrointestinal and genitourinary tracts) as well as the terminal spinal cord, is a more likely candidate for the constellation of anomalies seen in CS. This concept is supported by the generation of a CS phenotype in a mouse model using etretinate, a teratogen that targets the caudal cell mass. One proposed mechanism is a failure of dorsoventral separation of the caudal cell mass from the hindgut endoderm during late gastrulation. ${ }^{6}$

All the patients in our study had a first sacral vertebra that was morphologically normal, and in all but one, the second sacral vertebra was also preserved; this finding supports an etiology related to the caudal cell mass given that secondary neurulation occurs only distal to the posterior neuropore at the level of the second sacral vertebra. ${ }^{3}$ The nature of the dysraphic abnormalities encountered in these cases is also supportive of a disorder with its origins in secondary neurulation. Fatty filum and caudal type lipomas were the typical tethering pathologies, both considered to be secondary neurulation defects. By contrast, transitional and dorsal type lipomas were not seen in this series.

\section{Spinal Dysraphism in CS}

It is clear from this series that intraspinal anomalies are common in CS. Moreover, occult spinal dysraphism may significantly contribute to the pathology seen in CS. This is in keeping with a recent literature review that estimated that $60 \%$ of CS patients have at least one dysraphic anomaly ${ }^{13}$ Furthermore, patients with a solid presacral tumor invariably had a concurrent anterior meningocele or lipoma. Histopathological analysis in our series showed that the most common type of presacral mass was mature teratoma, which is in keeping with findings in the literature. However, anterior meningocele often contributed to the mass in the presacral space, and in one case the presacral mass was more histologically complex, consisting of various tissue types including meningeal elements. These findings further suggest a complex locoregional developmental anomaly. The example of a complex presacral tumor containing various tissue types is also in keeping with the development of this malformation early in embryogenesis, when the cellular specification of different tissue types is ongoing. The importance of adequately imaging the lumbosacral spine with MRI in cases of CS is therefore evident. This applies equally to patients presenting with anorectal malformations; the child who developed pyomyelia after instrumentation of the anorectal malformation serves to emphasize this point.

Given the significant spinal pathology demonstrated in our study and others, we believe the contribution of spinal dysraphism to the syndrome has been previously underrecognized. Since the caudal cell mass forms the substrate for secondary neurulation, it is likely that aberrant development of the caudal cell mass underlies the generation of multiple anomalies throughout the terminal spinal cord and the terminal gastrointestinal and genitourinary tracts. Therefore, we support the use of the term "syndrome" over the formerly used "triad" (referring specifically to the combination of sacral dysgenesis, anorectal malformation, and presacral mass). Indeed, we believe that the diagnostic criteria for CS should be reviewed, placing appropriate weight on each malformation according to its incidence in the literature. Under such criteria, perhaps spinal dysraphism-or more accurately, features of aberrant secondary neurulation-would play a more prominent and useful role in the early diagnosis and management of CS.

\section{Conclusions}

Although not part of the original triad, occult spinal dysraphism is a common, recognized feature of CS with the potential to contribute to long-term morbidity. The pattern of dysraphic anomalies observed is in keeping with a disorder of secondary neurulation. The surgical anatomy is typically favorable, and with the use of intraoperative neurophysiological monitoring, untethering can be performed safely and effectively. Where occult spinal dysraphism or spinal cord tethering is present, a single-stage combined operative approach to repair the spinal dysraphic anomalies and resect the presacral mass is an appropriate therapy that minimizes the number of surgical interventions, addresses multiple congenital malformations simultaneously, and is associated with good postoperative and longterm outcomes.

\section{References}

1. Belloni E, Martucciello G, Verderio D, Ponti E, Seri M, Jasonni V, et al: Involvement of the HLXB9 homeobox gene in Currarino syndrome. Am J Hum Genet 66:312-319, 2000

2. Chakhalian D, Gunasekaran A, Gandhi G, Bradley L, Mizell J, Kazemi N: Multidisciplinary surgical treatment of presacral meningocele and teratoma in an adult with Currarino triad. Surg Neurol Int 8:77, 2017

3. Copp AJ, Greene ND: Neural tube defects-disorders of neurulation and related embryonic processes. Wiley Interdiscip Rev Dev Biol 2:213-227, 2013 
4. Crétolle C, Pelet A, Sanlaville D, Zérah M, Amiel J, Jaubert F, et al: Spectrum of HLXB9 gene mutations in Currarino syndrome and genotype-phenotype correlation. Hum Mutat 29:903-910, 2008

5. Currarino G, Coln D, Votteler T: Triad of anorectal, sacral, and presacral anomalies. AJR Am J Roentgenol 137:395398,1981

6. Dias MS, Azizkhan RG: A novel embryogenetic mechanism for Currarino's triad: inadequate dorsoventral separation of the caudal eminence from hindgut endoderm. Pediatr Neurosurg 28:223-229, 1998

7. Duru S, Karabagli H, Turkoglu E, Erşahin Y: Currarino syndrome: report of five consecutive patients. Childs Nerv Syst 30:547-552, 2014

8. Emans PJ, Kootstra G, Marcelis CL, Beuls EA, van Heurn LW: The Currarino triad: the variable expression. J Pediatr Surg 40:1238-1242, 2005

9. Emans PJ, van Aalst J, van Heurn EL, Marcelis C, Kootstra G, Beets-Tan RG, et al: The Currarino triad: neurosurgical considerations. Neurosurgery 58:924-929, 2006

10. Emoto S, Kaneko M, Murono K, Sasaki K, Otani K, Nishikawa T, et al: Surgical management for a huge presacral teratoma and a meningocele in an adult with Currarino triad: a case report. Surg Case Rep 4:9, 2018

11. Ilhan H, Tokar B, Atasoy MA, Kulali A: Diagnostic steps and staged operative approach in Currarino's triad: a case report and review of the literature. Childs Nerv Syst 16:522-524, 2000

12. Isik N, Elmaci I, Gokben B, Balak N, Tosyali N: Currarino triad: surgical management and follow-up results of four [correction of three] cases. Pediatr Neurosurg 46:110-119, 2010

13. Kole MJ, Fridley JS, Jea A, Bollo RJ: Currarino syndrome and spinal dysraphism. J Neurosurg Pediatr 13:685-689, 2014

14. Kurosaki M, Kamitani H, Anno Y, Watanabe T, Hori T, Yamasaki T: Complete familial Currarino triad. Report of three cases in one family. J Neurosurg 94 (1 Suppl):158-161, 2001

15. Lee SC, Chun YS, Jung SE, Park KW, Kim WK: Currarino triad: anorectal malformation, sacral bony abnormality, and presacral mass-a review of 11 cases. J Pediatr Surg 32:5861, 1997

16. Marin-Sanabria EA, Nagashi T, Yamamoto K, Nakamura Y, Aihara H, Kohmura E: Presacral meningocele associated with hereditary sacral agenesis and treated surgically: evaluation in three members of the same family. Neurosurgery 57:E597, 2005

17. Martucciello G, Torre M, Belloni E, Lerone M, Pini Prato A,
Cama A, et al: Currarino syndrome: proposal of a diagnostic and therapeutic protocol. J Pediatr Surg 39:1305-1311, 2004

18. Massimi L, Calisti A, Koutzoglou M, Di Rocco C: Giant anterior sacral meningocele and posterior sagittal approach. Childs Nerv Syst 19:722-728, 2003

19. Merello E, De Marco P, Ravegnani M, Riccipetitoni G, Cama A, Capra V: Novel MNX1 mutations and clinical analysis of familial and sporadic Currarino cases. Eur J Med Genet 56:648-654, 2013

20. Otagiri N, Matsumoto Y, Yoshida Y: Posterior sagittal approach for Currarino syndrome with anterior sacral meningocele: a case report. J Pediatr Surg 35:1112-1114, 2000

21. Patel RV, De Coppi P, Kiely E, Pierro A: Currarino's syndrome in twins presenting as neonatal intestinal obstruction-identical presentation in non-identical twins. BMJ Case Rep 2014, 2014

22. Pio L, Piatelli G, Rossi A, Scarsi P, Merello E, Capra V, et al: Urological outcome in patients with Currarino syndrome. J Pediatr Surg 49:1643-1646, 2014

23. Samuel M, Hosie G, Holmes K: Currarino triad-diagnostic dilemma and a combined surgical approach. J Pediatr Surg 35:1790-1794, 2000

24. Yoshida A, Maoate K, Blakelock R, Robertson S, Beasley S: Long-term functional outcomes in children with Currarino syndrome. Pediatr Surg Int 26:677-681, 2010

\section{Disclosures}

The authors report no conflict of interest concerning the materials or methods used in this study or the findings specified in this paper.

\section{Author Contributions}

Conception and design: Thompson, Cearns, Hettige. Acquisition of data: Cearns, Hettige. Analysis and interpretation of data: Cearns. Drafting the article: Cearns. Critically revising the article: all authors. Reviewed submitted version of manuscript: Thompson, Cearns, De Coppi. Approved the final version of the manuscript on behalf of all authors: Thompson. Study supervision: Thompson.

\section{Correspondence}

Dominic N. P. Thompson: Great Ormond Street Hospital, London, United Kingdom. dominic.thompson@gosh.nhs.uk. 